Cristina dos Santos Padilha ${ }^{1}$ Walter Ferreira de Oliveira ${ }^{1}$

${ }^{1}$ Departamento de Saúde Pública, Centro de Ciências da Saúde, Universidade Federal de Santa Catarina. Campus Universitário, Trindade. 88040-900 Florianopolis SC. padilha.psico@gmail.com

\section{Representação social do terapeuta comunitário na rede SUS}

\author{
Social representation of the community therapist \\ in the Brazilian Unified Health System
}

Abstract The approval of the National Policy of Integrative and Complementary Practices fosters the provision of Community Therapy in the Brazilian Unified Health System (SUS). This initiative seeks to develop the necessary competencies to attend to the psychosocial demands in the professionals and the community leadership and to build support networks in order to extend the efficacy of Primary Health Care. This study aims to describe the social representation on the community therapist prepared by health care professionals employed at SUS. Semi-structured interviews were conducted with 27 professionals who were trained in Community Therapy in 2009 by the State Health Department of Santa Catarina in partnership with the Ministry of Health. Data analysis was carried out by descending hierarchical classification. The results revealed that there is a social representation among the professionals regarding what it signifies to be a community therapist, seen as someone who humanizes interpersonal relations in the health care sector. However, Primary Health Care professionals still subscribe to a less horizontalized group practice model than professionals working at the secondary level of care, represented in this study by the Psychosocial Care Centers (CAPS).

Key words Community therapy, Social representation, Unified Health System, Psychosocial Care Centers
Resumo A aprovação da Política Nacional de Práticas Integrativas e Complementares dá subsídios para implantar a Terapia Comunitária no Sistema Único de Saúde (SUS), visando desenvolver nos profissionais e nas lideranças comunitárias as competências necessárias para lidar com as demandas psicossociais e promover redes de apoio social, ampliando a resolutividade da Atenção Básica. O objetivo deste estudo é descrever a representação social sobre o Terapeuta comunitário elaborada por profissionais de saúde da rede SUS. Participaram 27 profissionais que realizaram a formação em Terapia Comunitária oferecida em 2009 pela Secretaria de Estado da Saúde de Santa Catarina em parceria com o Ministério da Saúde. A coleta de dados utilizou a entrevista individual semidirigida e a análise foi realizada por meio da classificação hierárquica descendente. Os resultados revelam que existe uma representação social dos profissionais sobre o que é ser terapeuta comunitário, entendido como alguém que humaniza as relações interpessoais no setor saúde. No entanto, os profissionais da Atenção Primária são legatários de um modelo de prática grupal menos horizontalizado que os profissionais da Atenção Secundária, nesse trabalho representada pelos Centros de Atenção Psicossocial (CAPS).

Palavras-chave Terapia comunitária, Representação social, Sistema Único de Saúde, Centro de Atenção Psicossocial 


\section{Introdução}

Este trabalho surge a partir de reflexões e inquietações sobre o atual processo de transformação dos serviços de saúde decorrente do movimento da Reforma Psiquiátrica. Experiências exitosas onde houve adequado investimento na territorialização dos serviços e na formação dos profissionais de saúde trazem a conviç̧ão de que os serviços substitutivos ao hospital psiquiátrico podem responder às demandas da população. A experiência tem mostrado também que a simples transformação da estrutura física dos serviços é insuficiente sem a adequada transformação de seu corpo técnico.

A Terapia Comunitária (TC) é uma metodologia de intervenção em comunidades que busca promover saúde através da construção de vínculos solidários, da valorização das experiências de vida dos participantes, do resgate da identidade, da restauração da autoestima e da ampliação da percepção dos problemas e possibilidades de resolução a partir das competências ${ }^{1}$.

A aprovação da Política Nacional de Práticas Integrativas e Complementares (PNPIC) em 2006 dá subsídios para estender essa prática, que já acontece há mais de vinte anos em Fortaleza, a outras regiões do país. Em 2008 firmou-se convênio entre o Ministério da Saúde e a Fundação Cearense de Pesquisa e Cultura para implantar a TC na Rede de Assistência à Saúde do Sistema Único de Saúde (SUS). O projeto visa desenvolver nos profissionais da área da saúde e nas lideranças comunitárias as competências necessárias para lidar, através do uso da TC, com os sofrimentos e as demandas psicossociais e promover redes de apoio social, ampliando a resolutividade da Atenção Básica².

A inserção da TC no SUS atende às proposições da Política Nacional de Atenção Básica, entre elas a implementação das diretrizes da Política Nacional de Humanização através do acolhimento, da realização da escuta qualificada das necessidades dos usuários e do estabelecimento de vínculo ${ }^{3,4}$. Responde também aos interesses da Política Nacional de Promoção da Saúde que tem como uma de suas diretrizes fortalecer a participação social, entendendo-a como fundamental na conse-cução de resultados de promoção da saúde, em especial a equidade e o empoderamento individual e comunitário, privilegiando as práticas de saúde sensíveis à realidade brasileira $^{5}$.

Para atingir tais resultados é fundamental que o terapeuta comunitário não exerça um saber hierarquizado em relação ao grupo em que intervém, respeitando as diferentes culturas, modos de ser, pensar e agir. É função do terapeuta comunitário valorizar a diversidade de experiências e suscitar sua partilha de forma horizontal e circular, promovendo uma corresponsabilidade do grupo pela busca de soluções e de superações das adversidades ${ }^{6}$.

As pesquisas sobre a TC no contexto da saúde coletiva têm se voltado para as repercussões desse instrumento na vida do usuário. Alguns estudos abordam a realidade da Atenção Básica, nos grupos específicos de TC ou nos grupos temáticos que ocorrem nas unidades de saúde, como grupos com gestantes ou idosos, e que incorporam essa metodologia ${ }^{1,7-13}$. Outros estudos se voltam para o contexto dos Centros de Atenção Psicossocial (CAPS), indicando a TC como um instrumento capaz de fomentar a construção da rede e explorar os recursos do território ${ }^{14-}$ ${ }^{16}$. Alguns autores discorrem ainda sobre a necessidade de capacitação dos profissionais da Estratégia Saúde da Família (ESF) para a promoção de um atendimento integral, o que requer lidar também com as demandas de saúde mental, apontando a TC como um instrumento que pode responder parcialmente a essa demanda profissional ${ }^{17-19}$.

A TC, inserida no SUS, surge como uma promessa de humanização das relações entre profissionais de saúde e usuários, capaz de fortalecer os vínculos humanos e empoderar as comunidades. O profissional de saúde exercendo a função de terapeuta comunitário deve relegar seu conhecimento técnico a um segundo plano e suscitar a troca de experiências de vida e um clima de acolhimento para o sofrimento cotidiano relatado pelos usuários participantes de um grupo de TC. Através dessa postura empática é possível que esteja se consolidando uma nova tecnologia para o acolhimento das demandas de saúde. No entanto, até o momento de realização do presente estudo, não foram encontradas pesquisas acerca do pensamento coletivo dos profissionais de saúde sobre essa nova tecnologia de cuidado.

Em Santa Catarina foram selecionados, em 2009, 35 profissionais de saúde para um curso de formação em TC financiado pelo Ministério da Saúde e pela Secretaria de Saúde do Estado. A relevância de tal proposta ancora-se na visão de que são necessários novos sujeitos e tecnologias apropriadas para encontrar respostas satisfatórias construídas coletivamente para atender às demandas de saúde da população. A necessidade, apontada pelos movimentos da Reforma Sa- 
nitária e da Reforma Psiquiátrica, de se implantar um modelo de atenção à saúde mental com base comunitária, priorizando-se a promoção da saúde e a prevenção do adoecimento, coincide com a proposta da TC de criar redes de apoio solidárias a indivíduos e famílias que vivenciam situação de sofrimento emocional ou psíquico. O presente trabalho resgata essa experiência de capacitação e objetiva descrever a representação social sobre o terapeuta comunitário elaborada por profissionais de saúde da rede SUS de Santa Catarina.

\section{Representações sociais}

O estudo da atividade representativa tem sido apreendido através de diferentes níveis de análise e perspectivas. No caso do estudo das representações sociais, o nível de análise que se salienta é aquele que reenvia o sujeito para as suas pertenças sociais e para as atividades de comunicação, e a representação para a sua funcionalidade e eficácia sociais ${ }^{20}$.

As representações sociais podem ser entendidas como sistemas que têm uma lógica e uma linguagem particulares, uma estrutura de implicações que assenta em valores e em conceitos, um estilo de discurso que lhes é próprio. São "teorias", "ciências coletivas" sui generis, de interpretação e elaboração do real. São produzidas coletivamente, mas para qualificá-las de social é preciso enfatizar sua função. E uma de suas funções é contribuir para os processos de formação de condutas e de orientação das comunicações sociais, engendrando interação $0^{21}$.

As representações sociais apresentam três dimensões: a atitude, a informação e o campo de representação ou imagem. A atitude é a mais frequente dessas três dimensões. Uma pessoa representa alguma coisa apenas depois de ter adotado uma posição, e em função da posição tomada. Essa abordagem clássica das representações sociais proposta por Moscovici é conhecida como Dimensional ${ }^{21}$.

O estudo das representações sociais é essencial para que se compreenda a cognição social, pois diz respeito a uma forma especial de se adquirir e comunicar conhecimento, uma forma que cria realidades e senso comum. Indivíduos e grupos não são receptores passivos, eles pensam de forma autônoma, constantemente produzindo e comunicando representações, conformando uma "sociedade pensante"22.

A noção de representação social implica sua relação com processos de dinâmicas social e psí- quica e com a elaboração de um sistema teórico também complexo em que por um lado deve-se considerar o funcionamento do aparelho cognitivo e do aparelho psíquico e, por outro, o funcionamento do sistema social, dos grupos e das interações, na medida em que afetam a gênese, a estrutura e a evolução das representações que são afetadas por sua intervenção. Por isso as representações sociais devem ser estudadas articulando-se elementos afetivos, mentais e sociais e integrando a consideração das relações sociais que afetam as representações e a realidade material, social e ideativa sobre a qual elas têm de intervir. As representações sociais são qualificadas como um saber prático porque remetem à experiência a partir da qual esse saber é produzido, aos contextos e condições em que é produzido, ao fato de que a representação serve para agir sobre o mundo e o outro, o que desemboca em suas funções e eficácia sociais ${ }^{23}$.

As representações são construídas socialmente através de discursos públicos nos grupos. Em segundo sentido, entretanto, esse conhecimento é criado pelo grupo. A interação entre as pessoas expressa e confirma suas crenças subjacentes; a representação social é sempre uma unidade do que as pessoas pensam e do modo como fazem. Por isso a representação é mais do que uma imagem estática de um objeto na mente das pessoas, ela compreende também seu comportamento e a prática interativa de um grupo. É ao mesmo tempo uma teoria sobre o conhecimento representado, assim como sobre a construção do mundo ${ }^{24}$.

O termo Representações Sociais refere-se, portanto, a um conjunto de fenômenos que ocorrem naturalmente entre grupos e à teoria construída para explicá-los. Sua proposição desencadeia um processo de renovação temática, teórica e metodológica da psicologia social. A atribuição desse termo e a inauguração do campo devem-se ao psicólogo social francês Serge Moscovici, que faz um primeiro delineamento formal a partir do trabalho La psychanalyse, son image et son public, em 1961. Nessa obra é investigado o fenômeno da socialização da psicanálise, de sua apropriação pela população parisiense e do processo de sua transformação para servir a outros usos e funções sociais ${ }^{25}$.

Moscovici escolhe Durkheim como ancestral para a sua teoria das representações sociais, contribuindo para classificar essa corrente francesa de pesquisa em psicologia social, iniciada no começo da era moderna, como uma forma sociológica de psicologia social. Ela se constitui numa importante crítica sobre a natureza individual da 
tradição dominante na psicologia social nos Estados Unidos, desafiando a hegemonia da psicologia social americana dentro da Europa ${ }^{26}$.

Moscovici parte do conceito de representação coletiva proposto por Durkheim, entendendo que tal conceito precisa ser circunscrito com maior rigor. Encarada de modo passivo, a representação é apreendida a título de reflexo, na consciência individual ou coletiva, de um objeto, de um feixe de ideias que lhe são exteriores. Nesse sentido a representação é comparada a uma imagem. Mas pode-se pensá-la de um modo ativo, consistindo seu papel em modelar o que é dado do exterior, na medida em que os indivíduos e os grupos se relacionam com objetos, atos e situações constituídos por miríades de interações sociais. Ela reproduz, é certo, mas essa reprodução implica um remanejamento das estruturas, uma remodelação dos elementos, uma verdadeira reconstrução do dado no contexto dos valores, das noções e das regras de que se torna doravante solidário. Aliás, o dado externo jamais é algo acabado e unívoco, ele deixa muita liberdade à atividade mental que se empenha em apreendê-lo. À concepção estática das representações coletivas de Durkheim Moscovici propõe a de representações sociais, concebendo-as como conjuntos dinâmicos, produção de comportamentos e de relações com o meio ambiente ${ }^{21}$.

\section{Método}

Este estudo caracterizou-se como exploratório e descritivo. Os participantes foram 27 profissionais de saúde capacitados em um curso de Terapia Comunitária oferecido pela Secretaria de Estado da Saúde de Santa Catarina, em parceria com o Ministério da Saúde. Ocorrido entre 2009 e 2010, o curso disponibilizou 35 vagas e priorizou capacitar trabalhadores da saúde e da assistência social da região do Vale do Itajaí, devido aos desastres ambientais ocasionados por chuvas e enchentes no final do ano de 2008 . O critério de inclusão dos sujeitos neste estudo foi a atuação profissional em serviços vinculados às Secretarias de Saúde dos municípios contemplados com o curso.

A coleta de dados, ocorrida em 2010, fez uso de entrevistas individuais semidirigidas, posteriormente transcritas e originando um corpus analisado pelo software ALCESTE, um dispositivo para exploração e descrição de questões abertas. Seu pressuposto é que pontos diversos de referência produzem diferentes maneiras de falar; o uso de um vocabulário específico é visto como uma fonte para detectar maneiras de pensar sobre um objeto.

O objetivo da análise com ALCESTE é, então, distinguir classes de palavras que representam diferentes formas de discurso a respeito do tópico de interesse ${ }^{27}$. O programa emprega análise de classificação hierárquica descendente, permitindo uma análise lexicográfica do texto e oferecendo contextos (classes) que são caracterizados por seu vocabulário e pelos segmentos de textos compartilhados. Depois da definição das Unidades de Contexto Inicial (UCI) processada pelo pesquisador, o programa divide e dimensiona o corpus, um conjunto textual monotemático, em segmentos de texto, que são as Unidades de Contexto Elementar (UCE), em função do seu tamanho e respeitando a pontuação ${ }^{28}$.

As linhas de comando, que precederam e codificaram cada UCI, foram compostas pelas seguintes variáveis: sexo, idade, escolaridade, renda familiar, cargo ocupado, experiência no cargo e nível de complexidade do serviço onde atua. $\mathrm{O}$ vocabulário mais significativo de cada classe foi selecionado com base em dois critérios: (a) palavras com frequência igual ou superior à frequência média do corpus (critério lexicográfico); (b) qui-quadrado de associação da palavra à classe estatisticamente significativa $\left(\chi^{2} \geq 3,84, \mathrm{gl}=1\right)$. Seguindo esses critérios, as palavras destacadas nos contextos foram analisadas e comparadas com intenção de definir o conteúdo apresentado pelos participantes em relação ao que é ser terapeuta comunitário.

O projeto foi aprovado pelo Comitê de Ética em Pesquisa com Seres Humanos da Universidade Federal de Santa Catarina, respeitando os preceitos da resolução 196/96 do Conselho Nacional de Saúde ${ }^{29}$. Todos os participantes assinaram o Termo de Consentimento Livre e Esclarecido.

\section{Resultados e Discussão}

\section{Caracterização dos participantes}

Participaram 27 profissionais de saúde da rede SUS de Santa Catarina, dos quais dezessete $(62,97 \%)$ atuam no interior do estado, na região do Vale do Itajaí (cidades de Apiúna, Blumenau, Gaspar, Indaial, Itajá́, Rodeio e Timbó) e dez $(37,03 \%)$ no litoral, nas cidades de Florianópolis e Palhoça.

Dentre os participantes, vinte $(74,07 \%)$ são do sexo feminino e sete $(25,93 \%)$ do sexo mas- 
culino, encontrando-se a maioria $(12-44,44 \%)$ com idade entre 30 e 39 anos, sete $(25,93 \%)$ entre 20 e 29 anos, cinco (18,52\%) entre 40 e 49 anos e somente três $(11,11 \%)$ na faixa etária compreendida entre 50 e 59 anos.

Em relação à renda familiar, quinze (55,56\%) profissionais enquadram-se na categoria entre cinco e 10 salários mínimos, seis $(22,22 \%)$ até cinco salários mínimos e os seis restantes $(22,22 \%)$ têm renda familiar superior a 10 salários mínimos.

Quanto à escolaridade, a maioria dos sujeitos tem especialização latu sensu (17 - 62,96\%), seguidos por profissionais com curso superior completo $(9-33,33 \%)$ e por um $(3,71 \%)$ profissional com curso técnico.

Em relação aos cargos ocupados, a maioria atua em equipes técnicas $(21-77,78 \%)$ e o restante na gestão $(4-14,81 \%)$ e em coordenações de serviços $(2-7,41 \%)$. A maioria dos profissionais tem de um a cinco anos de experiência no cargo (15 - 55,56\%), seguidos por aqueles com experiência entre seis e 10 anos (seis - 22,22\%), com experiência menor que um ano (4 - 14,81\%) e superior a 10 anos $(2-7,41 \%)$.

Dez participantes $(37,04 \%)$ estavam, à época do estudo, vinculados a serviços da Atenção Primária, treze $(48,15 \%)$ a serviços da Atenção Secundária (CAPS) e quatro $(14,81 \%)$ atuavam em órgãos de gestão de serviços de saúde.

\section{Representação social do Terapeuta Comunitário}

O corpus foi dividido em 140 UCE, das quais $71 \%$ foram consideradas na Classificação Hierárquica Descendente (CHD); 5.483 palavras foram analisadas e tiveram, em média, cinco ocorrências, sendo que as palavras com frequência inferior a cinco foram excluídas da apresentação dos dados. Das palavras encontradas 1.117 são de formas distintas.

Conforme o dendograma apresentado pela Figura 1, a CHD primeiramente dividiu o corpus original em dois subcorpora (1 a partição); de um lado temos a classe 3 se contrapondo às classes 1

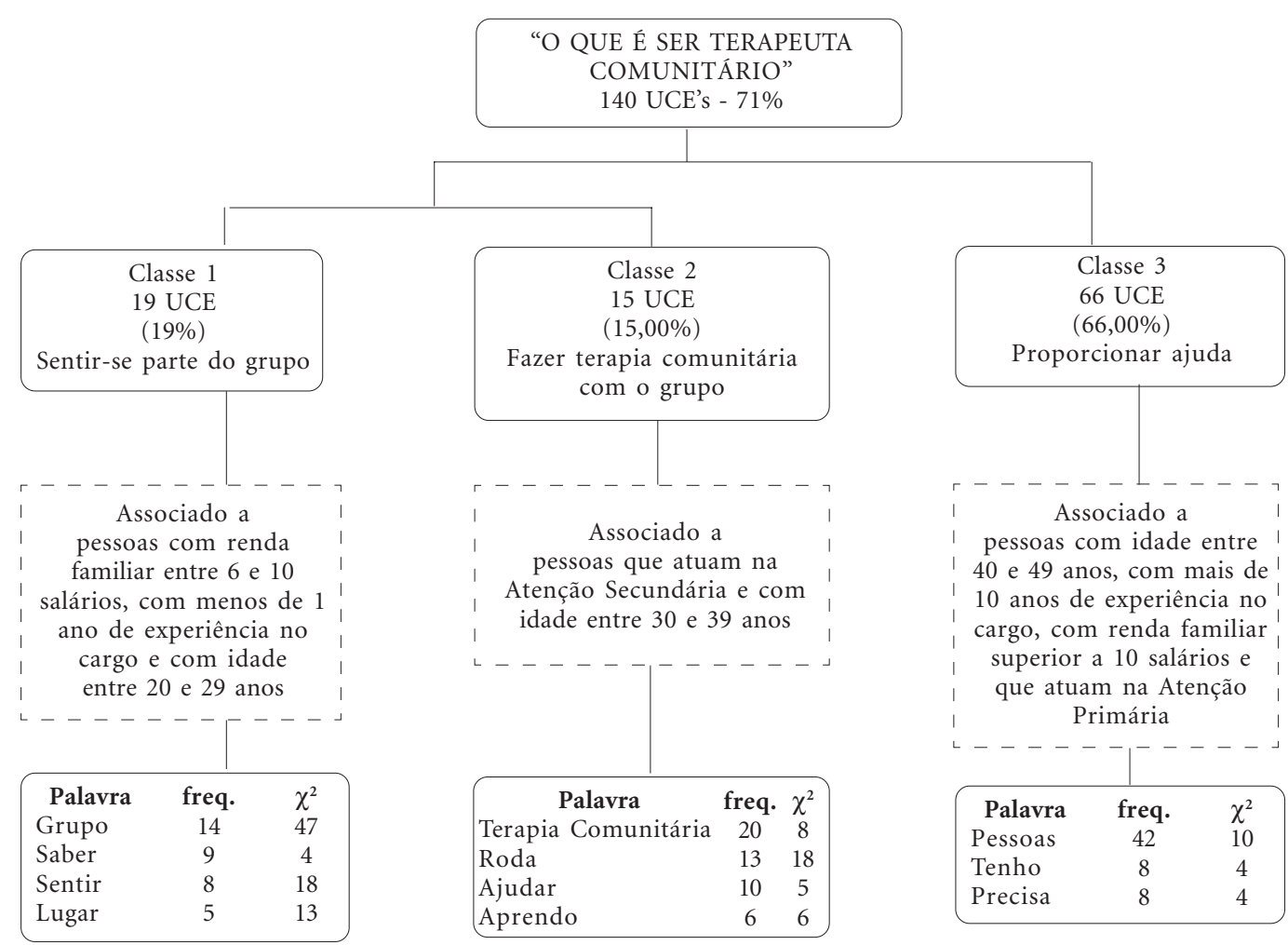

Figura 1. Dendograma do corpus Terapeuta Comunitário. 
e 2. Uma 2a partição, sobre o primeiro subcorpora separou a classe 1 da classe 2 . O resultado foi a obtenção de três classes.

A partir dos conteúdos das classes verifica-se que ser terapeuta comunitário, para estes profissionais, está relacionado com um sentimento de fazer parte do grupo (Classe 1), o que se complementa com a noção de fazer TC junto com o grupo (Classe 2), e que se contrapõem à noção de proporcionar ajuda (Classe 3 ).

\section{Classe 3. Proporcionar ajuda (66 UCE)}

Na classe 3, com 66\% das UCE, o terapeuta comunitário é concebido como alguém que proporciona ajuda, através de funções que lhe são específicas: coordenar, conduzir, acolher e mediar o grupo de TC. Estiveram mais significativamente associados a esta classe pessoas com idade entre 40 e 49 anos, com mais de 10 anos de experiência no cargo, com renda familiar superior a 10 salários e que atuam na Atenção Primária. As palavras representativas foram: pessoas, tenho, precisa. Seguem algumas passagens ilustrativas:

[...] às vezes uma animação, alguma coisa para tentar passar, porque eu, no fundo eu sinto que eu estou coordenando, eu não posso deixar a peteca cair tanto assim, quer dizer, passar para as pessoas que elas têm condições sim, por pior que esteja a situação [...] (Sujeito 09).

[...] eu tenho que ser só um condutor, um facilitador, um guia da solução. Eu teria dificuldade para definir, é mais uma coisa que eu sinto. Por exemplo, eu me realizo quando eu consigo ajudar (Sujeito 13).

[...] muitas vezes o paciente que lhe procura, ele às vezes quer lhe ouvir, quer ter um acolhimento. E isso a TC traz, lhe ensina a acolher. Não só de um profissional, mas às vezes de um monte de pessoas em uma roda. É tudo o que a pessoa quer: ouvir uma coisa no momento certo, no local certo, a palavra certa (Sujeito 24).

A preocupação expressa pelos profissionais, nestes trechos, é em ajudar, executar determinadas ações para garantir o efeito terapêutico do grupo, baseado naquilo que eles percebem como necessidades dos usuários. O terapeuta comunitário é o profissional que media o grupo e melhor poderá fazê-lo quanto maior for seu conhecimento e sua experiência.

A capacidade de ajuda, no entanto, não é atribuída exclusivamente ao profissional que conduz o grupo, considerado apenas um facilitador que deve suscitar o acolhimento nos demais integrantes, afinal são as trocas grupais que propor- cionam a melhoria dos vínculos interpessoais e que conferem à TC seu caráter preventivo.

\section{Classe 2. Fazer TC com o grupo (15 UCE)}

Essa classe foi característica de pessoas que atuam na Atenção Secundária (CAPS) e com idade entre 30 e 39 anos, responsável por 15\% das UCE. As palavras que mais se destacaram foram: Terapia Comunitária, roda, ajudar, aprendo. Nesta classe ser terapeuta comunitário é coordenar a roda, fazer com que o grupo se desenvolva dentro das regras, mas sem necessariamente realizar nenhum tipo de intervenção técnica. Ao mesmo tempo em que tem a função de coordenar o grupo o terapeuta comunitário faz terapia junto com o grupo, ajuda e é ajudado. Todos são responsáveis por encontrar soluções para os problemas, todos contribuem, conforme ilustram os trechos a seguir:

[...] para mim eu acho que na verdade a gente está fazendo uma TC também. A gente organiza, ministra, mas nós também estamos junto participando (Sujeito 02).

[...] então essa exigência profissional que a gente tem, a TC acaba sendo muito prazerosa também nesse sentido, porque todos participam, todos contribuem e todos têm essa habilidade de ajudar o outro e de contribuir (Sujeito 11).

[...] você é uma pessoa como qualquer outra que está ali, a diferença é que o terapeuta comunitário coordena os trabalhos da roda, mas não vai direcionar nada, não vai induzir nada, não vai interpretar nada, não vai fazer nenhum tipo de intervenção (Sujeito 12).

É recorrente, nas passagens que ilustram essa classe, a ideia de que apesar de estar coordenando o grupo o terapeuta comunitário não ocupa um lugar central, ele se coloca em igualdade de conhecimento com as demais pessoas, admitindo não ter respostas para tudo, confiando no grupo para dar encaminhamento às questões ali surgidas. Os profissionais se mostram aliviados de uma cobrança por resolutividade, já que naquele espaço o grupo é soberano e muitas vezes é o próprio grupo que transmite ensinamentos. O terapeuta comunitário é alguém que pode incorporar à sua prática a própria subjetividade, suas experiências, sua formação, sua cultura e, através das trocas com o grupo, ampliar seu conhecimento.

Classe 1. Sentir-se parte do grupo (19 UCE)

A classe 1 representa 19\% das UCE do corpus analisado. Nessa classe, ser terapeuta comunitá- 
rio tem relação com o sentimento de fazer parte do grupo, sendo a figura do terapeuta diluída nesse coletivo de pessoas, o que possibilita sentir-se mais próximo do usuário, reconhecer o saber do outro e se despir do saber técnico, propiciando que outras vozes sejam ouvidas. As palavras que mais representam essa classe são: grupo, saber, sentir, lugar. Contribuíram significativamente para esta classe pessoas com renda familiar entre seis e 10 salários mínimos, com menos de um ano de experiência no cargo e com idade entre 20 e 29 anos.

[...] ser terapeuta comunitário é se sentir mais próximo à comunidade, pertencente realmente à comunidade e ao grupo (Sujeito 10).

[...] eu no lugar de terapeuta comunitário, eu acho um lugar legal. Eu acho um exercício de se despir do sujeito do suposto saber. Se sustentar esse lugar não tem terapia comunitária, não tem circularidade de informação, não tem (Sujeito 20).

É um fazer parte. Porque geralmente nas outras atividades de grupo você acaba coordenando. Claro que tem uma coordenação, tem umas regras, alguns passos para seguir, mas a gente se sente muito mais parte daquilo ali (Sujeito 22).

Conforme os trechos apresentados, quando coordenam os grupos de TC os profissionais sentem que estão ocupando um lugar que lhes proporciona estar integrados ao grupo, fazendo parte do grupo. Esse lugar ocupado pelo profissional de saúde requer delegar ao próprio grupo a efetividade terapêutica dessa prática, evocando da comunidade o conhecimento advindo de suas experiências de vida, oportunizando trocas e acolhendo.

As três classes de palavras do corpus referente ao conhecimento construído pelos profissionais de saúde a respeito do que é ser terapeuta comunitário são aqui interpretadas como diferentes aspectos de uma representação social. O pensamento coletivo dos profissionais da rede SUS de Santa Catarina que praticam a TC revela ser o terapeuta comunitário alguém que promove a humanização das relações interpessoais no setor saúde, não se limitando sua função ao grupo de TC, já que os aprendizados advindos dessa prática são aplicados de forma mais abrangente no cotidiano de trabalho.

Embora nas três classes o terapeuta comunitário seja concebido em sua função de coordenação do grupo, a classe 1, Sentir-se parte do grupo parece se aproximar da classe 2, Fazer TC com o grupo, no que concerne a um contexto grupal de relações mais horizontalizadas, diferenciando-se da classe 3, Proporcionar ajuda. Nesta última, o terapeuta comunitário se diferencia do restante do grupo na medida em que é a ele atribuída, embora não de forma exclusiva, a capacidade de ajudar, através das intervenções e mediações que realiza no grupo. As três classes obtidas corroboram a proposta idealizada por Barreto ${ }^{6}$, quem concebe o terapeuta comunitário como alguém que valoriza a diversidade de experiências e suscita sua partilha de forma horizontal e circular, promovendo uma corresponsabilidade do grupo pela busca de soluções e de superações das adversidades.

Contextualizando este estudo à luz das contribuições da Teoria das Representações Sociais ${ }^{21-}$ ${ }^{24}$, é possível afirmar que os profissionais entrevistados partilham um conhecimento sobre o que é ser terapeuta comunitário. Este conhecimento partilhado funciona como um guia para suas práticas de TC e para outras no âmbito da saúde coletiva. Ao final, é percebida uma contribuição para a humanização das relações interpessoais através da valorização do contexto grupal e comunitário, de uma postura de acolher e compartilhar vivências e de proporcionar ajuda.

Embora não seja objetivo específico deste trabalho, é possível apontar elementos atitudinais e imagéticos, característicos da abordagem Dimensional $^{21}$, na representação social dos profissionais de saúde sobre o terapeuta comunitário. Isto aparece, por exemplo, em falas que se referem a ser terapeuta comunitário como ocupar um "lugar legal" ou um "lugar especial", "fazer bem e sair bem do grupo", "ser transformado como profissional”. Estas posturas acompanham, por sua vez, a dimensão da informação, mais apreensível nas classes de palavras apresentadas anteriormente, conformando esse saber coletivo que contribui para a humanização na saúde.

Embora as três classes de palavras descritas anteriormente evidenciem aspectos de uma mesma representação (a promoção da humanização), tais aspectos podem influir e sofrer influência dos diferentes contextos em que acontecem as práticas de TC, pois como discorre Wagner ${ }^{24}$, a representação é mais do que uma imagem estática de um objeto na mente das pessoas, compreendendo também seu comportamento e a prática interativa de um grupo. Dessa forma, os profissionais da Atenção Primária são legatários de um modelo de prática grupal menos horizontalizado que os profissionais da Atenção Secundária, neste trabalho representada pelos Centros de Atenção Psicossocial (CAPS).

Os CAPS são serviços que sugiram como suporte à Reforma Psiquiátrica, visando transformar um modelo de atenção à saúde mental cen- 
trado no manicômio em um modelo com foco no território. Talvez a singularidade da tarefa de promover saúde mental, característica da proposta desses serviços, e a necessidade de um enfoque transdisciplinar que responda à complexidade de tal demanda configurem posturas profissionais diferenciadas, favorecendo relações intergrupais mais horizontalizadas, tais como as propostas nos grupos de TC. Como postula Vasconcelos $^{30}$, muitas práticas em serviços brasileiros de saúde mental que se inspiram na proposta da desinstitucionalização formulada pela Psiquiatria Democrática italiana implicam um sério questionamento e recolocação em novas bases dos princípios e da formação convencional aprendidos pelos profissionais nos cursos universitários tradicionais. Exigem uma cultura institucional nova nos serviços, capaz de oferecer um clima favorável para este processo de reelaboração de suas identidades profissionais originais, bem como uma democratização efetiva das relações de poder nas equipes, apesar de todos os atravessamentos em contrário.

É possível, pois, afirmar que a iniciativa de capacitação dos profissionais de saúde em TC é uma forma de valorização profissional, contribuindo para o aperfeiçoamento desses sujeitos e proporcionando-lhes uma nova forma de acolhimento. A prática da TC além de fomentar as grupalidades contribui para a valorização dos sujeitos que conformam o grupo, uma vez que todos são vistos como dotados de potencial e solicitados a ajudar. Desta forma estimula-se a coparticipação e a construção de redes solidárias. A horizontalidade das relações entre o profissional que conduz o grupo e os demais participantes e o resgate da subjetividade e das experiências de vida auxiliam a vinculação e a construção da clínica ampliada.

\section{Considerações finais}

O convênio firmado entre o Ministério da Saúde e a Fundação Cearense de Pesquisa e Cultura para implantar a TC na Rede de Assistência à Saúde do SUS visa desenvolver nos profissionais da área da saúde e nas lideranças comunitárias as competências necessárias para lidar com os sofrimentos e demandas psicossociais e promover redes de apoio social, ampliando a resolutividade da Atenção Básica.

O pensamento coletivo dos profissionais participantes deste estudo aponta para o terapeuta comunitário como alguém que promove a humanização das relações interpessoais no setor saúde, não se limitando sua função ao grupo de TC, uma vez que os aprendizados advindos dessa prática são aplicados de forma mais abrangente no cotidiano de trabalho. No entanto, os profissionais da Atenção Primária são legatários de um modelo de prática grupal menos horizontalizado que os profissionais da Atenção Secundária, nesse trabalho representada pelos Centros de Atenção Psicossocial (CAPS).

$\mathrm{O}$ entendimento das representações sociais como conhecimentos partilhados pode situar o número de participantes dessa investigação como um fator limitante para o estudo desse fenômeno. Por outro lado, até o momento da coleta de dados havia apenas uma turma de 35 profissionais capacitados para atuar como terapeutas comunitários na rede SUS de Santa Catarina, fato que torna o grupo participante representativo. Além disso, a estratégia de capacitação do Ministério da Saúde em TC tem como base os estados. Neste sentido, o estudo em um estado, tomado como unidade, pode ser considerado, no contexto das abordagens qualitativas, para a exploração das representações sociais. Outra limitação que pode ser aqui relatada é a ausência de estudos sobre a atividade representativa no campo das Práticas Integrativas e Complementares, o que limita o diálogo dos resultados aqui encontrados. 


\section{Colaboradores}

CS Padilha responsabilizou-se por elaborar o projeto de pesquisa, coletar e analisar os dados e WF Oliveira foi orientador de mestrado da autora principal, coeditou e revisou o artigo.

\section{Referências}

1. Andrade FB, Ferreira Filha MO, Dias MD, Silva AO, Costa ICC, Lima EAR, Mendes CKTT. Promoção da saúde mental do idoso na atenção básica: as contribuições da terapia comunitária. Texto \& Contexto Enfermagem 2010; 9(1):129-136.

2. Brasil. Ministério da Saúde (MS). Portaria n. ${ }^{\circ}$ 971, de 03 de maio de 2006. Aprova a Política Nacional de Práticas Integrativas e Complementares (PNPIC) no Sistema Único de Saúde. Diário Oficial da União 2006; 4 maio.

3. Brasil. Ministério da Saúde (MS). Política Nacional de Promoção da Saúde. Brasília: MS; 2006.

4. Brasil. Ministério da Saúde (MS). Humaniza SUS: documento base para gestores e trabalhadores do SUS. 4a Edição. Brasília: Editora do Ministério da Saúde; 2008.

5. Ministério da Saúde (MS). Política Nacional de Atencão Básica. Brasília: MS; 2006.

6. Barreto AP. Terapia Comunitária passo a passo. Fortaleza: Gráfica LCR; 2005.

7. Filha MOF, Dias MD, Andrade FB, Lima EAR, Ribeiro FF, Silva MSS. A Terapia Comunitária como estratégia de promoção à saúde mental: o caminho para o empoderamento. Rev Eletrônica de Enfermagem 2009; 11(4):964-970. [acessado 2010 abr 12]. Disponível em: http://www.fen.ufg.br/revista/v11/ n4/pdf/v11n4a22.pdf

8. Guimarães MBL, Valla VV. Terapia Comunitária como expressão de educação popular: um olhar a partir dos encontros com agentes comunitários de saúde. In: 32a Reunião Anual da ANPED; 2009; Caxambú, MG. [acessado 2010 maio 1]. Disponível em: http://www.anped.org.br/reunioes/32ra/arquivos /trabalhos/GT06-5115-Res.pdf

9. Rocha IA, Braga LAV, Tavares LM, Andrade FB, Filha MOF, Dias MD, Silva AO. A Terapia Comunitária como um novo instrumento de cuidado para a saúde mental do idoso. Revista Brasileira de Enfermagem REBEn 2009; 62(5):687-694.

10. Souza AJF, Matias GN, Gomes KFA, Parente ACM. A saúde mental no Programa de Saúde da Família. Revista Brasileira de Enfermagem REBEn 2007; 60(4):391-395.

11. Victor JF, Vasconcelos FF, Araújo AR, Ximenes LB, Araujo TL. Grupo Feliz Idade: cuidado de enfermagem para a promoção da saúde na terceira idade. Revista da Escola de Enfermagem da USP 2007; 41(4):724-730.

12. Guimarães FJ. Repercussões da Terapia Comunitária no cotidiano de seus participantes [dissertação]. João Pessoa (PB): Universidade Federal da Paraíba; 2006.

13. Holanda VR. A Contribuição da Terapia Comunitária para o enfrentamento das inquietações das gestantes [dissertação]. João Pessoa (PB): Universidade Federal da Paraíba; 2006.

14. Ferreira Filha MO, Carvalho MAP. A Terapia Comunitária em um Centro de Atenção Psicossocial: (des)atando pontos relevantes. Rev Gaúcha de Enfermagem 2010; 31(2):232-239. [acessado 2011 maio 14]. Disponível em: http://seer.ufrgs.br/RevistaGauchadeEnfermagem/article/view/11739/10230. 
15. Mota TD. As necessidades de saúde da perspectiva dos usuários de um serviço comunitário de saúde mental [dissertação]. São Paulo (SP): Universidade de São Paulo; 2007.

16. Machado DM. A desconstrução do manicômio inter no como determinante para a inclusão social [dissertação]. Brasília (DF): Universidade de Brasília; 2006.

17. Silva ALC. Terapia comunitária como abordagem complementar no tratamento da depressão: Uma Estratégia de Saúde Mental no PSF de Petrópolis/RJ [dissertação]. Rio de Janeiro (RJ): Universidade Estácio de Sá; 2010.

18. Soares CSDA. Terapia Comunitária na Estratégia de Saúde da Família: implicações no modo de andar a vida dos usuários [dissertação]. Ribeirão Preto (SP): Universidade de São Paulo; 2008.

19. Fukui L, Marchetti, LB. Terapia Comunitária. Uma forma de atuação no espaço público. In: Congresso Brasileiro de Terapia Comunitária; 2004; Brasília, DF. [acessado 2010 maio 1]. Disponível em: http:// www.usp.br/nemge/textos_tecendo_estudando/ terapiacomun_espacopublico_fukui.pdf.

20. Vala J. Representações sociais: para uma psicologia social do pensamento social. In: Vala J, Monteiro MB, organizadores. Psicologia social. $7^{\circ}$ Edição. Lisboa: Fundação Calouste Gulbenkian; 2006. p. 353-384.

21. Moscovici S. Representação Social da Psicanálise. Rio de Janeiro: Zahar Editores; 1978.

22. Moscovici S. On social representation. In: Forgas JP, organizador. Social Cognition. London: European Association of Experimental Social Psychology, Academic Press; 1981. p. 181-209.

23. Jodelet D. Representações sociais: um domínio em expansão. In: Jodelet D, organizadora As representações sociais. RJ: Ed. UERJ; 2001. p.17-44.

24. Wagner W. Sócio-gênese e características das representações sociais. In: Moreira ASP, Oliveira DC organizadores. Estudos interdisciplinares de representações sociais. Goiânia: AB; 1998. p. 3-22.
25. Sá CP. Representações Sociais: o conceito e o estado atual da teoria. In: Spink MJ, organizadora. $O$ conhecimento no cotidiano - As representaçoes sociais na perspectiva da psicologia social. SP: Editora Brasiliense; 1993. p. 19-45.

26. Farr R. As raízes da Psicologia Social Moderna. Petrópolis: Vozes; 1998.

27. Kronberger N, Wagner W. Palavras-chave em contexto: análise estatística de textos. In: Bauer MW, Gaskell G, editores. Pesquisa qualitativa com texto, imagem e som: um manual prático. 7a Edição. RJ: Vozes; 2008. p. 416-441.

28. Camargo BV. Alceste: Um programa informático de análise quantitativa de dados textuais. In: Moreira ASP, Camargo BV, Jesuíno JC, Nóbrega SM, organizadores. Perspectivas teórico-metodológicas em representações sociais. João Pessoa: UFPB Editora Universitária; 2005. p. 511-540.

29. Brasil. Ministério da Saúde (MS). Conselho Nacional de Saúde. Resolução nº 196 de 10 de outubro de 1996. Diretrizes e Normas Regulamentadoras de Pesquisas Envolvendo Seres Humanos. Diário Oficial da União 1996; 16 out.

30. Vasconcelos EM. Complexidade e pesquisa interdis ciplinar: epistemologia e metodologia operativa. RJ: Vozes; 2007.

Artigo apresentado em 04/06/2012

Aprovado em 11/04/2012

Versão final apresentada em 16/06/2012 